\title{
The effects of self-controlled and instructor-controlled feedback on motor learning and intrinsic motivation among novice adolescent taekwondo players
}

\author{
Reza Goudini*, Saeed Ashrafpoornavaee, and Alireza Farsi \\ Faculty of Sport Sciences, Shahid Beheshti University, Tehran, Iran
}

Copyright: (c) 2019 R. Goudini et al. This is an open access article licensed under the Creative Commons Attribution License (https://creativecommons.org/licenses/by/4.0/).

\begin{abstract}
Background: Although the useful effects of self-controlled feedback on motor skills learning have been proven, a study dealing with the effects of self-controlled and instructor-controlled feedback on learning and intrinsic motivation among novice taekwondo players has so far not been conducted. Objective: The purpose of the present study was to examine the effects of self-controlled and instructor-controlled feedback on learning the ap chagi technique and intrinsic motivation among novice adolescent taekwondo players. Methods: Thirty participants (12.43 \pm 2.08 years) were selected purposefully and homogeneously based on pre-test scores. They were categorized in the three groups, namely self-control, yoked, and instructor-control. The acquisition phase consisted of 100 ap chagi in 10 blocks of 10 trials. The practices were done over four days and the retention test was conducted 48 hours after the last practice session. The Intrinsic Motivation Inventory was administered to evaluate participants' subjective experience associated with the target task. The task included the ap chagi technique that contained five sub-scales were derived from the evaluation form of World Taekwondo Federation for rating the trials. Mixed and one-way ANOVA models were utilized to analyze the data. Results: The results demonstrated that self-control group have better ap chagi performance during retention test compared to other groups $(p=.007)$. Moreover, the results of intrinsic motivation questionnaire indicated that motivation of self-control group was higher, especially in terms of perceived competence $(p=.004)$ than the other two groups. Conclusion: The results of this study confirmed the usefulness of self-controlled feedback for motor learning by way of an ap chagi technique task. Feedback also affects a learner's intrinsic motivation, which, in turn, seems to improve learning.
\end{abstract}

Keywords: front kick, self-controlled feedback, taekwondo

\section{Introduction}

The importance of feedback as an educational tool is undeniable; however, issues such as accuracy, type, and frequency of feedback are not favorable in athletic and educational environments (Janelle, Kim, \& Singer, 1995). Most of the experimental research have studied the informational function of feedback that provides data about the performance of athletes. According to guidance hypothesis, low frequency of feedback as well as feedback to non-successful trials and significant errors, at the time of leading to correct motion, are more effective than feedback to successful trials and minor errors. This hypothesis asserts that exposing a learner to a great deal of external,

\footnotetext{
* Address for correspondence: Reza Goudini, Department of Physical Education \& Sport Science, Shahid Beheshti University, Evin, Tehran, 1983963113, Iran. E-mail: goudini.reza@gmail.com
}

augmented feedback during practice may lead the learner to develop a detrimental dependency on this type of feedback. This may result in better performance during practice but weak performance at transfer is an indication of poor motor learning (Salmoni, Schmidt, \& Walter, 1984). Recent studies in this context have formulated a particular attitude toward motivational role of augmented feedback for motor learning (Wulf \& Shea, 2004). These findings suggest that motivational role of feedback can have a direct effect on motor learning (Badami, VaezMousavi, Wulf, \& Namazizadeh, 2011, 2012; Chiviacowsky \& Wulf, 2007; Chiviacowsky, Wulf, Wally, \& Borges, 2009; Saemi, Porter, Ghotbi-Varzaneh, Zarghami, \& Maleki, 2012; Saemi, Wulf, Varzaneh, \& Zarghami, 2011). Researchers have focused their efforts on understanding the role of learner autonomy in motor skill acquisition (Sanli, Patterson, Bray, \& Lee, 2013). Considering recent studies, self-control feedback is 
one of the most interesting research areas in motor skill learning. It should be noted that self-controlled feedback has been used in relation to augmented feedback (Chiviacowsky, de Medeiros, Kaefer, Wally, \& Wulf, 2008; Chiviacowsky \& Wulf, 2002, 2007; Grand et al., 2015; Janelle, Barba Frehlich, Tennant, \& Gauraugh,1997; Janelle et al., 1995; Patterson \& Carter, 2010), videotape (Aiken, Fairbrother, \& Post, 2012; Hartman, 2005; Patterson \& Carter, 2010), body guiding (Wulf, Clauss, Shea, \& Whitacre, 2001), practice amount (Post, Fairbrother, \& Barros, 2011), task planning (Keetch \& Lee, 2007), and sport tools choice and task difficulty (Andrieux, Danna, \& Thon, 2012). In all these studies, self-control during retention or transfer test promoted performance in comparison with controlled conditions (yoked condition). For example, Chiviacowsky et al. (2008) examined the effect of self-controlled feedback on motor learning in children. The results confirmed the notion that selfcontrolled feedback enhances children's motor learning in comparison with that of the yoked group.

Janelle et al. (1997), Hartman (2005), and Wulf (2007) concluded that if they allow participants to make decision in regard to the time of receiving feedback in practice conditions, learning will be improved. According to the literature, self-controlled feedback gives learners the opportunity to decide by themselves about when to receive feedback. Accordingly, their motor learning and performance can be enhanced (Chiviacowsky \& Wulf, 2002, 2005). The research of Patterson and Carter (2010) explored the relationship of task learning to multiple scheduling purposes. Aiken et al. (2012) dealt with the relation of video feedback to performance knowledge. Chiviacowsky, Wulf, Machado, and Rydberg (2012) analyzed the relation of learning of affected people to Down syndrome. Fairbrother, Laughlin, and Nguyen (2012) examined the relation of low and highly active people and the effective generalizability of self-control feedback conditions in learning process improvement. Hemayattalab (2014) investigated the effects of self-control and instructor-control feedback on motor learning in individuals with cerebral palsy. They demonstrated that self-control feedback is more effective than instructor-control feedback in motor task learning among individuals with cerebral palsy as it is among the average population.

Research results of Alikhani, Gharaat, Naghdi, Eidi, and Alikhani (2013) showed that feedback in selfcontrol conditions especially feedback that is received after trial performance from instructor-control leads to better learning in difficult motor tasks. Task difficulty is one of the pivotal components of a learner's needs during practice sessions. The task difficulty should be adjusted according to the practitioners' skill level, because it should reach an optimum with regard to "challenge point" (Guadagnoli \& Lee, 2004) in order to enhance skill acquisition and skill learning; a task difficulty which is lower or higher than optimum, will deteriorate the learning condition (Andrieux et al., 2012). Moreover, Carter and Patterson (2012) have referred to the effectiveness of self-control feedback on motor learning among youth rather than adults by drawing from strategic approach and error recognition. Research has shown that providing practice conditions with positive feelings at the time of performance results in enhanced self-confidence (Badami et al., 2012), and self-efficacy (Koka \& Hein, 2003; Mouratidis, Vansteenkiste, Lens, \& Sideridis, 2008).

Chiviacowsky and Wulf (2002) studied the effects of self-controlled feedback on the motivational factors for the first time. They claimed that one of the advantages of self-controlled condition is its effect on increasing motivation. These results were obtained again in studies done on the effects of feedback after good trials versus poor trials (Badami et al., 2011; Chiviacowsky et al., 2009; Saemi et al., 2011). In addition, feedback following good trials increased intrinsic motivation, perceived competence and enjoyment/interest (Amorose \& Horn, 2000; Badami et al., 2011). Regarding the importance of feedback in taekwondo, Lim et al. (2015) concluded that the pattern of self-controlled feedback can be adopted as a training strategy during the sessions of prolonged and difficult serial skills such as Taekwondo. Moreover, the results revealed that self-controlled feedback is associated with functions such as boosting deep, complex cognitive processing. The effect of self-controlled feedback on intrinsic motivation in the domains of motor leaning is very important, because intrinsic motivation is a catalyst for facilitating motor skill learning and performance. Regarding the ap chagi, the technique is a very linear kick. The practitioner raises the knee to the waist, pulls the toes back and quickly extends the foot towards the target. It is also known as the snap kick. The front kick is one of the first kicks learned in taekwondo and it is so much easier to learn than other techniques. As a consequence, considering the importance of self-control feedback on the one hand and inadequate research about field techniques in taekwondo on the other hand, the purpose of the present study is to compare the effect of self-control and instructor-control feedback (knowledge of performance) on learning of the ap chagi technique and intrinsic motivation among novice adolescent taekwondo athletes. The findings of this study can be helpful for coaches in case they tend to use feedback, especially its motivational role. 


\section{Methods}

\section{Participants}

Thirty male participants having no prior taekwondo experience, ranging in age from 10 to $15(12.43 \pm 2.08)$ years, were chosen from Rahiyan taekwondo club in Tehran. They participated in the present study voluntarily. Informed consent was obtained from the parents, and assent was obtained from the children. This study was approved by the local institutional review board.

\section{Procedures}

Prior to data collection, the participants were thoroughly informed about the task and feedback procedures. All participants were selected purposefully and homogeneously based on pre-test scores. Then, they were assigned homogeneously to one of the three experimental feedbacks group self-controlled feedback group $(n=10)$, the instructor-controlled feedback group $(n=10)$, and the yoked group $(n=10)$. The self-control feedback group was told that they would be allowed to access feedback of their performance about 5 out of 10 trails during acquisition. The instructorcontrol feedback group received feedback in 5 out of 10 trials whenever that instructor wanted. Lastly, in the yoked group, each participant was given feedback in accordance with a schedule that was developed by his or her counterpart in the self-controlled group. The acquisition phase included one hundred trials of ap chagi ( 10 blocks of 10 trials) with a feedback 5 out of 10 in four days. There are 10 seconds and 3 minutes intervals between each trial and each practice block respectively. The practice phase was done over 4 days ( 6 blocks over 2 days and 4 blocks over 2 days) and at the end of acquisition phase, the following actions and tests were conducted: the acquisition test, completion of intrinsic motivation questionnaire, retention test (48 hours later). The retention test included ten trials without feedback. They were also notified that they would not receive feedback during retention testing.

The task included the ap chagi technique that contained five sub-scales of feet movements, hands state, appropriate speed and power, balance, and the last shock. The given sub-scales were derived from the evaluation form (basic movements) of World Taekwondo Federation for rating the trials. All of the trials were rated by an international taekwondo referee after each trial. In order to determine their performance level, each one was assigned from one to five points based on five-point scale. On the whole, each participant got score between 5 and 25 points.

For reliability testing, participants performing the ap chagi task test twice at one week apart. Test reliability was measured with test-retest correlation coefficients (.92).

The Intrinsic Motivation Inventory (IMI; McAuley, Duncan, \& Tammen, 1989) was administered to evaluate participants' subjective experience associated with the target task. The IMI is a multidimensional measurement device that has been conducted in wide range of studies related on intrinsic motivation (e.g., Badami et al., 2011; Grand et al., 2015; Saemi et al., 2011). The instrument evaluates participants' interest/enjoyment, perceived competence, effort/importance, value usefulness, felt pressure and tension, and perceived choice with performing a given task, hence rendered six subscale scores.

A nine-item questionnaire comprising of the interest/enjoyment, perceived competence, and effort/ importance subscales of the IMI was modified for use in the current study. Three items from each of the subscales revealed a student's general level of interest/ enjoyment, perceived competence, and effort/importance. Particularly, we used the items described below.

Interest/enjoyment: 1. Ap chagi was fun to do. 2. While I was doing ap chagi, I was thinking about how much I enjoyed it. 3. I thought ap chagi was a boring task (reverse order - R).

Perceived competence: 4. After ap chagi for a while, I felt competent. 5. I am satisfied with my ap chagi performance. 6 . Ap chagi was a task that I couldn't do very well $(\mathrm{R})$.

Effort/importance: 7. I didn't try very hard to do well at ap chagi (R). 8. It was important to me to do well at ap chagi technique. 9. I tried very hard while doing ap chagi.

Response on the 7-point Likert-type scale ranged from 1 = strongly disagree to 7 = strongly agree. Negatively worded items were rescaled before data analysis. Internal consistency of each subscale was calculated using Cronbach's $\alpha$ statistics. They were superior: interest/enjoyment (.90), perceived competence (.82), and effort/importance (.85). The three subscales were summed to produce a composite measure of intrinsic motivation (Badami et al., 2011).

The IMI has been translated into Persian and it is well adapted for use with children (Badami et al., 2011; Grand et al., 2015; Saemi et al., 2011).

\section{Statistical analysis}

Shapiro-Wilk test showed normal data distribution, thus analysis of variance (ANOVA) for repeated measures (group: self-control, yoked, instructor control; time: 11 measurements) was used. A one-way ANOVA was also used to compare retention test performances and intrinsic motivation scores with the significance level of $p<.05$. Effect size was reported as $\eta^{2}$ (small $=.01$, 
average $=.06$, and large $=.14$ ) for mixed ANOVA and partial eta squared $\left(\eta_{p}^{2}\right)$ for one-way ANOVA. For measuring reliability (test-retest) of scores given by the rater (international referee), the Pearson correlation coefficient has been used. SPSS was used for data analysis (Version 16; SPSS, Chicago, IL, USA).

\section{Results}

The results obtained from all three groups (self-controlled, yoked and instructor-controlled; 10 blocks; see Figure 1) using ANOVA with repeated measures on the second factor indicated that the main effect of the block is considered to be significant $(F(2,27)=22.94$, $\left.p=.004, \eta^{2}=.45\right)$; but, the interaction effect of group $\times$ block $(F(2,27)=2.12, p=.87)$ and the main effect of the given group were not significant $(F(2,27)=0.96$, $p=.39)$. Consequently, there was no significant difference among the three groups in the acquisition phase. Whereas, there was a significant difference in the retention test $\left(F(2,27)=5.93, p=.007, \eta^{2}=.30\right)$. The Bonferroni post hoc test showed better performance for the self-control group in comparison to the other groups in the retention test $(p<.05)$.

Additionally, the results of the one-way ANOVA demonstrated that there is significant difference among the three groups in the following subscales of intrinsic motivation (see Table 1): interest/enjoy $\left(F(2,27)=3.71, \quad p=.003, \quad \eta_{\mathrm{p}}^{2}=.21\right), \quad$ perceived competence $\left(F(2,27)=10.69, p=.004, \eta_{\mathrm{p}}^{2}=.44\right)$, and effort/importance $(F(2,27)=5.52, \quad p=.044$, $\left.\eta_{\mathrm{p}}^{2}=.29\right)$. Moreover, a similar result was found for the total score of intrinsic motivation $(F(2,27)=9.29$, $\left.p=.004, \eta_{\mathrm{p}}^{2}=.40\right)$. The results of Tukey post hoc test showed the superiority of participants' self-control in subscales interest/enjoy and effort/importance over the group of instructor-control $(p<.05)$. Moreover, the given superiority was likely in subscale perceived competence and total score of intrinsic motivation $(p<.05)$ in comparison to the yoked and instructorcontrolled feedback group in statistical terms.

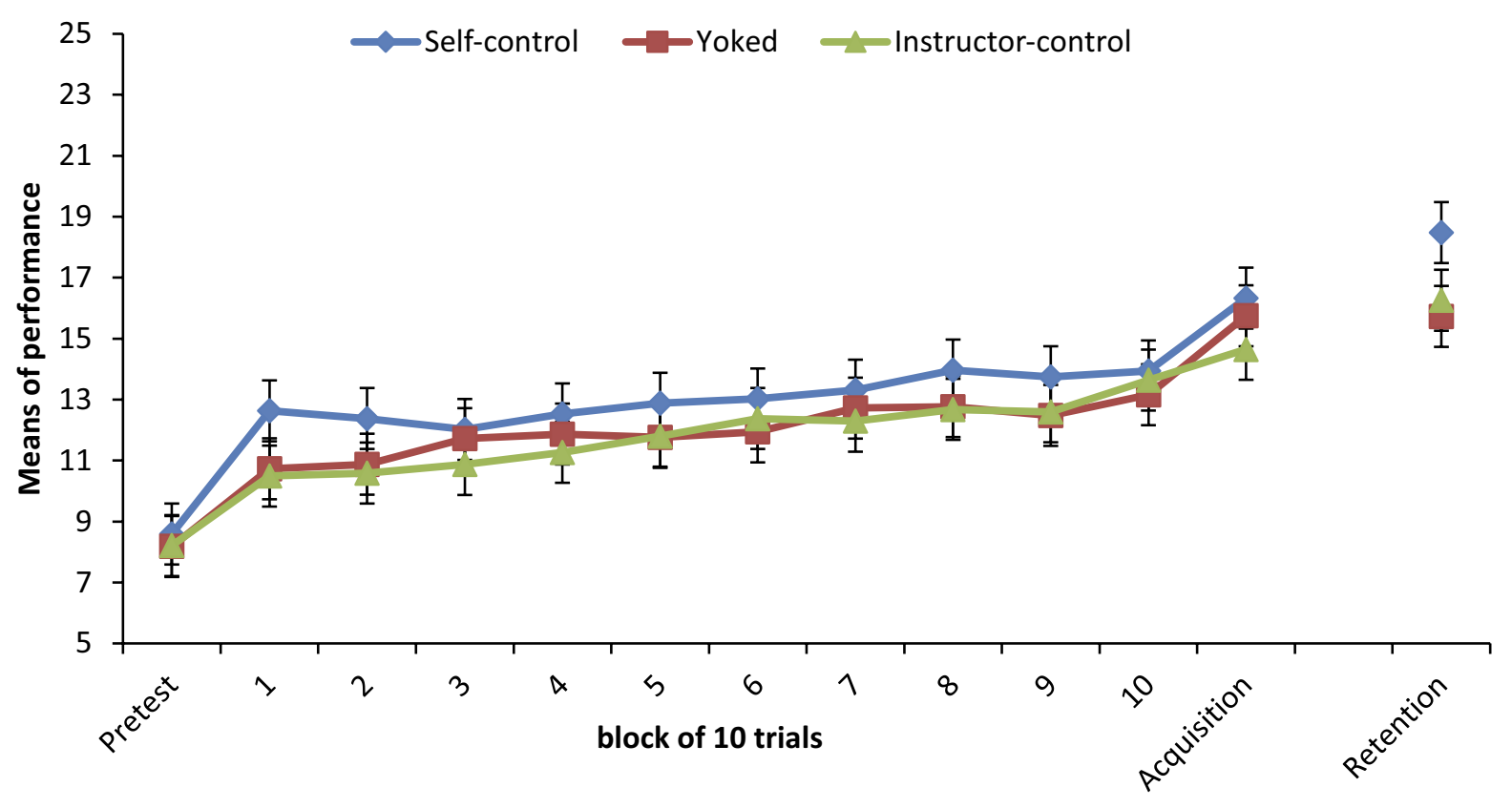

Figure 1. The means of ap chagi performance among the three groups in acquisition phase and retention test.

Table 1

The average of intrinsic motivation among the three groups

\begin{tabular}{|c|c|c|c|c|c|c|}
\hline \multirow[b]{2}{*}{ Subscale } & \multicolumn{2}{|c|}{ Self-control } & \multicolumn{2}{|c|}{ Yoked } & \multicolumn{2}{|c|}{ Instructor-control } \\
\hline & Mean & $S D$ & Mean & $S D$ & Mean & $S D$ \\
\hline Interest/enjoy & 17.1 & 3.6 & 14.2 & 3.2 & 13.6 & 2.3 \\
\hline Perceived competence & 18.0 & 2.0 & 12.9 & 3.2 & 13.3 & 2.8 \\
\hline Effort/importance & 16.7 & 4.0 & 13.6 & 3.5 & 11.6 & 2.7 \\
\hline Total score & 51.8 & 7.7 & 40.7 & 7.9 & 38.5 & 6.3 \\
\hline
\end{tabular}




\section{Discussion}

Although recent studies have shown that self-controlled feedback leaves positive effects on motor skill learning (Chiviacowsky \& Wulf, 2002, 2005), intended effects on particular motor skill learning such as the ap chagi technique among novice adolescent taekwondo athletes have not been explored so far. Therefore, the purpose of the present study was to compare the effect of self-control and instructor-control feedback (knowledge of performance) on learning of the ap chagi technique and intrinsic motivation among novice adolescent taekwondo athletes. The findings of the acquisition phase indicated that regardless of the progress during the aforementioned phase, there was no significant difference among the three given groups. These findings were in line with the studies of Chiviacowsky and Wulf $(2002,2005)$, Chiviacowsky et al. $(2008,2012)$, but they are in contrast with the results of Aiken et al. (2012), Fairbrother et al. (2012), Carter and Patterson (2012), Alikhani et al. (2013), and Lim et al. (2015). Friedrich and Mandl (1997) claimed that based on the cognitive view, the self-controlled condition put more pressure on the subjects. They should make decisions about their learning in accordance with their abilities and knowledge about how and when to request feedback. The learner should make different decisions and control the spectrum of freedom. This factor exerts more pressure on the learner. On the other hand, opposite approach of motivational and cognitive processes during acquisition phase lead to a similar performance in the self-control group as well as the instructor-controlled and yoked groups. However, in the retention and transfer test, all the groups are in the same situation. In other words, the self-control group is not affected by cognitive load and it can present the positive effects of self-control.

Regarding the effects of feedback types in ap chagi technique learning, the findings of this study confirm the previous research, such as Chiviacowsky and Wulf (2002, 2005), Chiviacowsky et al. (2008, 2012), Patterson and Carter (2010), Carter and Patterson (2012), Aiken et al. (2012), and Hemayattalab (2014). Except for the acquisition phase, the results showed that those subjects who receive self-control feedback in the retention test have a better performance in comparison to the other groups (yoked and instructor-control feedback). The results of previous research done in the field of self-control feedback supported this point as a facilitating factor at the time of motor skill learning (Alikhani et al., 2013; Carter \& Patterson 2012; Chiviacowsky \& Wulf, 2002, 2005; Fairbrother et al., 2012; Lim et al., 2015; Patterson \& Carter 2010). In addition, Lim et al. (2015) argue that the self-controlled feedback group had significantly superior performance compared to the yoked-feedback group in terms of acquisition and retention on the learning a serial motor skill.

According to Zimmerman (2000) the effects of selfcontrol conditions on learning improvement are related to participants' self-supervision and self-guidance and, by extension, to clarification and performance stability. Whereas, based on McNevin, Wulf, and Carlson (2000), the main reason for the success of people in this condition was related to participants' motivational enhancement. Chiviacowsky and Wulf (2005) concluded that motivational effect is not the only reason for advantageous self-control feedback. They contended that the relation of this feedback type and its relationship with the participants' deficiencies can be regarded as another reason. To Hartman (2005), the immediate recognition and correction that take place in self-control conditions are among the advantages of learning in selfcontrol conditions. It seems that practice conditions accompanied with self-control feedback compromise more with participants' needs. By way of explanation, consider the learner who requests feedback and feels mistrust about his performance on the one hand and the desired state in which feedback is provided to prove that the movement has been done correctly.

In research that dealt with the positive effects of feedback on learning, it is recognized that positive feedback encourages learners to achieve the intended purpose. In addition, it increases their hope for future performances (West, Bagwell, \& Dark-Freudeman, 2005). Studying the effect of motivational feedback in self-control conditions was commenced by Chiviacowsky and Wulf (2002). They showed that motivational factors are responsible for self-control conditions and the resultant advantages. Regarding the effect of feedback on positive and successful trials, the same results were obtained in the research of Chiviacowsky and Wulf (2007), Saemi et al. (2011), and Badami et al. (2011). In a similar vein, the present study aimed as well to investigate the effect of self-control feedback on the intrinsic motivation of participants. To this end, the motivation of all three groups was compared with one another using a questionnaire. The result showed that the self-control group was significantly better than the other two groups in all variables especially perception competence. Chiviacowsky and Wulf (2002), Patterson and Carter (2010), and Aiken et al. (2012) referred to participants' preference in receiving feedback to successful trials. Moreover, positive motivational feedback, perception competence, and intrinsic motivation (Ávila, Chiviacowsky, Wulf, \& Lewthwaite, 2012; Badami et al., 2011; Saemi et al., 2011) increased subjects' self-confidence and self-efficacy (Badami et al., 2011; Saemi et al., 2012). According to Koka and Hein 
(2003), the positive feedback has additional effect on perception competence, effort, and pleasure.

The similarity of this study with that of Vallerand and Reid (1984) and Amorose and Weiss (1998) emphasizes the continuation of the approach of the present study in an extensive range. By the same token, the research findings of Wulf, Chiviacowsky, and Lewthwaite (2012) showed that the increase of abilities in participants' attitude can have a positive and immediate effect on learning and motor performance among old adults. After all, the individual's perception of self-efficacy and self-evaluative progress leads to their performance improvement and promotion of learning. Therefore, each person's perception of his/her selfefficacy affects not only thinking and acting patterns but also motivation and beliefs toward his/her ability and the expected results from his/her actions. Taking into account the limitations of present study, it is recommended to keep in mind factors such as individual, environment, mastery level, and sport type (individual and group sports) in motor skills learning in subsequent research. The results of the present study may have educational implications for educational environments such as physical education classes, motor skills and rehabilitation education centres.

\section{Conclusion}

Regarding the research findings, we conclude that using the self-control method in motor skills can be effective in task learning among adolescent athletes and it can increase intrinsic motivation among children.

\section{Conflict of interest}

There were no conflicts of interest.

\section{References}

Aiken, C. A., Fairbrother, J. T., \& Post, P. G. (2012). The effects of self-controlled video feedback on the learning of the basketball set shot. Frontiers in Psychology, 3, 338.

Alikhani, H., Gharaat, M., Naghdi, N., Eidi, L., \& Alikhani, M. (2013). Effect of error detection and time of decision making for request feedback in self-controlled conditions acquisition and retention of a complex task. Annals of Biological Research, 4(2), 22-29.

Amorose, A. J., \& Horn, T. S. (2000). Intrinsic motivation: Relationships with collegiate athletes' gender, scholarship status, and perceptions of their coaches' behavior. Journal of Sport and Exercise Psychology, 22, 63-84.
Amorose, A. J., \& Weiss, M. R. (1998). Coaching feedback as a source of information about perceptions of ability: A developmental examination. Journal of Sport and Exercise Psychology, 20, 395-420.

Andrieux, M., Danna, J., \& Thon, B. (2012). Self-control of task difficulty during training enhances motor learning of a complex coincidence-anticipation task. Research Quarterly for Exercise and Sport, 83, 27-35.

Ávila, L. T., Chiviacowsky, S., Wulf, G., \& Lewthwaite, R. (2012). Positive social-comparative feedback enhances motor learning in children. Psychology of Sport and Exercise, 13, 849-853.

Badami, R., VaezMousavi, M., Wulf, G., \& Namazizadeh, M. (2011). Feedback after good versus poor trials affects intrinsic motivation. Research Quarterly for Exercise and Sport, 82, 360-364.

Badami, R., VaezMousavi, M., Wulf, G., \& Namazizadeh, M. (2012). Feedback about more accurate versus less accurate trials: Differential effects on self-confidence and activation. Research Quarterly for Exercise and Sport, 83, 196-203.

Carter, M. J., \& Patterson, J. T. (2012). Self-controlled knowledge of results: Age-related differences in motor learning, strategies, and error detection. Human Movement Science, 31, 1459-1472.

Chiviacowsky, S., de Medeiros, F. L., Kaefer, A., Wally, R., \& Wulf, G. (2008). Self-controlled feedback in 10-year-old children: Higher feedback frequencies enhance learning. Research Quarterly for Exercise and Sport, 79, 122-127.

Chiviacowsky, S., \& Wulf, G. (2002). Self-controlled feedback: Does it enhance learning because performers get feedback when they need it? Research Quarterly for Exercise and Sport, 73, 408-415.

Chiviacowsky, S., \& Wulf, G. (2005). Self-controlled feedback is effective if it is based on the learner's performance. Research Quarterly for Exercise and Sport, 76, 42-48.

Chiviacowsky, S., \& Wulf, G. (2007). Feedback after good trials enhances learning. Research Quarterly for Exercise and Sport, 78, 40-47.

Chiviacowsky, S., Wulf, G., Machado, C., \& Rydberg, N. (2012). Self-controlled feedback enhances learning in adults with Down syndrome. Brazilian Journal of Physical Therapy, 16, 191-196.

Chiviacowsky, S., Wulf, G., Wally, R., \& Borges, T. (2009). Knowledge of results after good trials enhances learning in older adults. Research Quarterly for Exercise and Sport, 80, 663-668.

Fairbrother, J. T., Laughlin, D. D., \& Nguyen, T. V. (2012). Self-controlled feedback facilitates motor learning in both high and low activity individuals. Frontiers in Psychology, 3, 323 .

Friedrich, H. F., \& Mandl, H. (1997). Analyse und Förderung selbstgesteuerten Lernens [Analysis and promotion selfdirected learning]. In F. E. Weinert \& H. Mandl (Eds.), Psychologie der Erwachsenenbildung (pp. 237-293). Göttingen, Germany: Hogrefe.

Grand, K. F., Bruzi, A. T., Dyke, F. B., Godwin, M. M., Leiker, A. M., Thompson, A. G., ... Miller, M. W. (2015). Why self-controlled feedback enhances motor learning: Answers from electroencephalography and indices of motivation. Human Movement Science, 43, 23-32. 
Guadagnoli, M. A., \& Lee, T. D. (2004). Challenge point: A framework for conceptualizing the effects of various practice conditions in motor learning. Journal of Motor Behavior, 36, 212-224.

Hartman, J. M. (2005). An investigation of learning advantages associated with self-control: Theoretical explanation and practical application (Unpublished doctoral dissertation). University of Virginia, Charlottesville, VA.

Hemayattalab, R. (2014). Effects of self-control and instructor-control feedback on motor learning in individuals with cerebral palsy. Research in Developmental Disabilities, 35, 2766-2772.

Janelle, C. M., Barba, D. A., Frehlich, S. G., Tennant, L. K., \& Cauraugh, J. H. (1997). Maximizing performance feedback effectiveness through videotape replay and a selfcontrolled learning environment. Research Quarterly for Exercise and Sport, 68, 269-279.

Janelle, C. M., Kim, J., \& Singer, R. N. (1995). Subjectcontrolled performance feedback and learning of a closed motor skill. Perceptual and Motor Skills, 81, 627-634.

Keetch, K. M., \& Lee, T. D. (2007). The effect of self-regulated and experimenter-imposed practice schedules on motor learning for tasks of varying difficulty. Research Quarterly for Exercise and Sport, 78, 476-486.

Koka, A., \& Hein, V. (2003). Perceptions of teacher's feedback and learning environment as predictors of intrinsic motivation in physical education. Psychology of Sport and Exercise, 4, 333-346.

Lim, S., Ali, A., Kim, W., Kim, J., Choi, S., \& Radlo, S. J. (2015). Influence of self-controlled feedback on learning a serial motor skill. Perceptual and Motor Skills, 120, 462-474.

McAuley, E., Duncan, T., \& Tammen, V. V. (1989). Psychometric properties of the Intrinsic Motivation Inventory in a competitive sport setting: A confirmatory factor analysis. Research Quarterly for Exercise and Sport, 60, 48-58.

McNevin, N. H., Wulf, G., \& Carlson, C. (2000). Effects of attentional focus, self-control, and dyad training on motor learning: Implications for physical rehabilitation. Physical Therapy, 80, 373-385.

Mouratidis, A., Vansteenkiste, M., Lens, W., \& Sideridis, G. (2008). The motivating role of positive feedback in sport and physical education: Evidence for a motivational model. Journal of Sport and Exercise Psychology, 30, 240-268.

Patterson, J. T., \& Carter, M. (2010). Learner regulated knowledge of results during the acquisition of multiple timing goals. Human Movement Science, 29, 214-227.
Post, P. G., Fairbrother, J. T., \& Barros, J. A. (2011). Selfcontrolled amount of practice benefits learning of a motor skill. Research Quarterly for Exercise and Sport, 82, 474-481.

Saemi, E., Porter, J. M., Ghotbi-Varzaneh, A., Zarghami, M., \& Maleki, F. (2012). Knowledge of results after relatively good trials enhances self-efficacy and motor learning. Psychology of Sport and Exercise, 13, 378-382.

Saemi, E., Wulf, G., Varzaneh, A. G., \& Zarghami, M. (2011). Feedback after good versus poor trials enhances motor learning in children. Revista Brasileira de Educação Física e Esporte, 25, 673-681.

Salmoni, A. W., Schmidt, R. A., \& Walter, C. B. (1984). Knowledge of results and motor learning: A review and critical reappraisal. Psychological Bulletin, 95, 355-386.

Sanli, E. A., Patterson, J. T., Bray, S. R., \& Lee, T. D. (2013). Understanding self-controlled motor learning protocols through the self-determination theory. Frontiers in Psychology, 3, 611 .

Vallerand, R. J., \& Reid, G. (1984). On the causal effects of perceived competence on intrinsic motivation: A test of cognitive evaluation theory. Journal of Sport Psychology, 6, 94-102.

West, R. L., Bagwell, D. K., \& Dark-Freudeman, A. (2005). Memory and goal setting: The response of older and younger adults to positive and objective feedback. Psychology and Aging, 20, 195-201.

Wulf, G. (2007). Self-controlled practice enhances motor learning: Implications for physiotherapy. Physiotherapy, 93, 96-101.

Wulf, G., Chiviacowsky, S., \& Lewthwaite, R. (2012). Altering mindset can enhance motor learning in older adults. Psychology and Aging, 27, 14-21.

Wulf, G., Clauss, A., Shea, C. H., \& Whitacre, C. A. (2001). Benefits of self-control in dyad practice. Research Quarterly for Exercise and Sport, 72, 299-303.

Wulf, G., \& Shea, C. H. (2004). Understanding the role of augmented feedback: The good, the bad and the ugly. In A. M. Williams \& N. J. Hodges (Eds.), Skill acquisition in sport: Research, theory and practice (pp. 121-144). London, United Kingdom: Routledge.

Zimmerman, B. J. (2000). Attaining self-regulation: A social cognitive perspective. In M. Boekaerts, P. R. Pintrich, \& M. Zeidner (Eds.), Handbook of self-regulation (pp. 13-39). San Diego, CA: Academic Press. 